\title{
Effects of Kurdistan Honey on the Tongue of Chemotherapy Treated Albino Rats (Immunohistochemical Study)
}

\author{
Ali Sultan Al-Refai ${ }^{1}$, Lukman Fawzi ${ }^{1}$ and Ameera Kamal Khalii ${ }^{2^{*}}$ \\ ${ }^{1}$ Department of Oral \& Maxillofacial Surgery, College of Dentistry, Hawler Medical University, Erbil, Kurdistan Region of Iraq \\ ${ }^{2}$ Department of Oral Diagnosis, College of Dentistry, Hawler Medical University, Erbil, Kurdistan Region of Iraq
}

"Corresponding author: Ameera Kamal Khalil, Department of Oral Diagnosis, College of Dentistry, Hawler Medical University, Erbil, Kurdistan Region of Iraq, Tel: 009647504882164; E-mail: amera1kam@yahoo.com

Rec date: Jul 16, 2014, Acc date: Aug 21, 2014, Pub date: Aug 23, 2014

Copyright: $\odot 2014$ Al-Refai AS, et al. This is an open-access article distributed under the terms of the Creative Commons Attribution License, which permits unrestricted use, distribution, and reproduction in any medium, provided the original author and source are credited.

\begin{abstract}
Background and Objectives: Mucositis can be a dose-limiting toxicity of cancer chemotherapy with direct effects on patient survival; therefore an effective intervention is considered a high priority in cancer patient. The aim of the present study was to evaluate the effectiveness of honey as a preventive treatment for the methotrexate (MTX) induced oral mucositis.
\end{abstract}

Materials and Methods: In current study forty females Albino rats, weighing 250-300 g were used in the study. For the induction of oral mucositis, $60 \mathrm{mg} / \mathrm{kg}$ of MTX was administered intraperitoneally to each animal in the study group at day 4 . The control animals were intraperitoneally injected by normal saline in the same manner and dose like MTX.

At the beginning of the experiment, the rats in each group were randomly divided into two groups: Distilled water treated group and honey treated group (10 animals each). A volume of distilled water equal to honey was given by intragastric gavage tube, while the other group was gavaged with honey at a dose of $2.5 \mathrm{~g} / \mathrm{kg}$ two times daily (with a total of $5 \mathrm{~g} / \mathrm{kg} /$ day). The animals were sacrificed at day 8 . In each experiment, the middle third of tongue was removed for histopathological and immunohistochemical analysis using Ki-67 and Bcl-2 immunolabeling.

Results: The result showed that, the MTX/honey group showed a significant increase in the thickness of the epithelium $(p<0.01)$, significant decrease in the number of congested blood vessels in the connective tissue of rat tongue mucosa $(p<0.01)$, non significant increase in the Ki-67 immune expression $(p>0.01)$, and significant increase in $\mathrm{Bcl}-2$ immune expression $(p<0.01)$ in comparison with the methotrexate/water group.

Conclusion: Natural honey at a concentration of $(5 \mathrm{~g} / \mathrm{kg} /$ day) produced protection against methotrexate induced tongue mucositis and therefore can be used as a protective natural product to oral mucosa against methotrexate induced cytotoxicity.

Keywords: Mucositis; Tongue; Honey; Methotrexate

\section{Introduction}

Cancer is a broad group of diseases involving unregulated cell growth. In cancer, cells divide and grow uncontrollably, forming malignant tumors, and invading nearby parts of the body and may also spread to more distant parts of the body. It is characterized by a series of cellular and genetic changes [1]. The treatment usually involves chemotherapy, radiotherapy, or surgery, either as a single therapy or in combination. Methotrexate (MTX) represents one of the most potent anti-tumor drugs, it was used at higher doses as a cancer therapy and it is used at much lower doses to treat rheumatic diseases and psoriasis [2]. Methotrexate is an antimetabolite inhibiting dihydrofolatereductase blocking the reduction of dihydrofolate to tetrahydrofolic acid. Depletion of tetrahydrofolic acid leads to a decreased thymidylate and purine biosynthesis, resulting in a decreased DNA synthesis. This effect on reducing DNA formation and cell turnover is responsible for both the therapeutic effect and the more common side effects [3].
Mucositis is the inflammation and ulceration of the mucosal membranes and it is one of the side effects of chemotherapy and radiotherapy. Unfortunately such therapy affects all rapidly dividing cells whether neoplastic or not. Consequently, the lining of the oral cavity, like the ventral tongue mucosa is at high risk of side effects [4].

Oral mucositis is an inflammatory, painful, and debilitating condition, occurs in 30 to $40 \%$ of patients receiving chemotherapy, $60 \%$ of patients receiving radiation therapy and $92 \%$ of patients receiving both chemotherapy and radiation therapy [5]. It is caused by a multi-step biological process, it is an inflammatory response of the oral mucosa that pathophysiology is complex and multifactorial. Histopathological evaluation of mucositis lesions shows mucosal thinning, caused by apoptosis and depletion of the epithelial basal layer, with subsequent denudation, its begin in the epithelium but then progress to involve the connec $\neg$ tive tissue [6].

The difficulty in eating and drinking was reported in nearly $90 \%$ of the examined patients with oral mucositis, and resultant weight loss in approximately $85 \%$ [7]. It can also lead to a reduction in total dose delivered to the tumor bed and unscheduled treatment breaks. This 
can have a detrimental effect on local tumor control and thus patient survival [8].

Honey is the substance made when the nectar and sweet deposits from plants are gathered, modified and stored in the honeycomb by honey bees. Honey has antibacterial, anti-viral, anti-fungal and antioxidants properties, and can be used for treatment of nausea, cough, cold, and effective against cancer growth [9]. Topically applied honey was also used for treatment of radiation - induced mucositis in cancer patients [10].

Chemotherapy-induced oral mucositis is an important doselimiting and costly side effect for which there is no definitive prophylaxis or treatment. The current study was aimed to evaluate the preventive role of honey ( $5 \mathrm{~g} / \mathrm{kg} /$ day) administered by gastric gavage for the MTX-induced tongue cytotoxicity. As variables to evaluate the grade of protection, we used histological and immunohistochemical investigations to clarify its effect on cell proliferation and cell apoptosis.

\section{Materials and Methods}

\section{Rats and housing}

In current study forty females Albino rats, weighing 250-300 g were supplied and cared in the Animal House of College of Medicine, Hawler Medical University, Erbil, Kurdistan Region of Iraq. The animals were kept under a standard laboratory conditions and maintained on a 12 hour light/dark cycle at $20 \pm 5^{\circ} \mathrm{C}$, fed with a standard rat chow and allowed to drink water ad libitum. The research project was approved by the Research Ethics Committee at College of Dentistry, Hawler Medical University under protocol.

\section{Preparation of honey}

Natural unprocessed raw honey was obtained from Merkasour, Kurdistan region of Iraq. The initial solution of honey was freshly prepared by dissolving $50 \mathrm{~g}$ of this brown, thick, and sticky honey in $40 \mathrm{ml}$ of distilled water (one $\mathrm{ml}$ contain $1.25 \mathrm{~g}$ honey). The mixture was filtered first with a fine muslin cloth and then with filter paper (Whatman no.1).

\section{Induction of mucositis}

Fijlstra et al. [11] found that the typical clinical signs of mucositis, such as a decreased food intake, weight loss, and diarrhea, were present in most methotrexate treated rats $(60 \mathrm{mg} / \mathrm{kg})$ from the second day until the fifth day of the experiment, after which rats started to recover. In the fourth day of the experiment, the histological and clinical symptoms of the induced mucositis were most severe. For this reason the animals were scarified four days after intraperitoneal injection of MTX. Al-Refai et al. (2014) found that doses of MTX less than this dose can cause oral mucositis [12].

\section{Experimental design}

The rats were randomly divided into two groups:

Control groups: Consist of distilled water treated group and honey treated group (10 animals each), the treatment continue for eight days. In the distilled water treated group, a volume of distilled water equal to honey was given with gavage tube, while the honey-treated group was gavaged with honey at a dose of $2.5 \mathrm{~g} / \mathrm{kg}$ two times daily, with a total of
$5 \mathrm{~g} / \mathrm{kg} /$ day [13]. A physiological saline $(0.9 \% \mathrm{NaCl})$ in a similar dose of MTX $(60 \mathrm{mg} / \mathrm{Kg})$ interrupt the treatment at day four and administered intraperitoneally instead of MTX.

Study or MTX- treated groups: Consist also of distilled water treated group and honey treated group (10 animals each), the treatment continue for eight days. They were gavaged by distilled water or by honey in a similar way like control group, but intraperitoneal injections of the MTX interrupted the treatment at day four.

\section{Histopathological analysis}

The animals were sacrificed by over dose of anesthesia at day 8 and the middle third of the tongue was removed for histopathological analysis. Samples were then fixed in neutral buffered $10 \%$ formalin, processed for $\mathrm{H} \& \mathrm{E}$, and for immunohistochemical analysis using $\mathrm{Bcl}-2$ and Ki-67 immunolabeling.

For histological analyses, the picture captured at $400 \mathrm{x}$ magnification, and three microscopic fields from each cheek mucosal epithelium section were registered between the external epithelial surface and the epithelial crista (major epithelial thickness) and performed in each of the three photograph fields. At every 10 measurements of epithelial thickness, one was repeated to assess intraexaminer reproducibility. All analysis was blind to the type of the sample. The presence of inflammatory infiltration was also evaluated at 400x magnification, and each microscopical field was labeled 0 (absence of inflammatory cells) or 1 (presence of inflammatory cells) respectively. For assessment of the number of blood vessels in each field, structures with endothelial lining and with red blood cells in their interior were counted at 20x magnification. At every 10 fields, a count was repeated to assess intra examiner reproducibility. All analysis was blind to the origin of the sample.

\section{Immunohistochemical stains and analysis using Ki-67 and Bcl-2 immunolabeling}

Cell proliferation was assessed by Ki-67 immunohistochemistry, while the anti apoptosis was assessed by Bcl-2 immunostaining and were performed using monoclonal Mouse Anti-Human Ki-67 Antigen, Clone MIB-1, Code No. M 7240 staining system, and a monoclonal Mouse Anti-Human BcL-2 Oncoprotien Clone 124 Code No 1587 ready to use $\mathrm{N}$-series primary antibody, for use with DakoEnVision TM , EnVision TM double staining and LASAB TM 2 systems. The staining procedure sections of the instructions included with each detection system were followed. Positive and negative controls were run simultaneously with biopsy specimen.

Positive cells expressing Ki-67 were identified by brown nuclei, while Bcl-2 was demonstrated brown cytoplasmic staining. To ensure the objectivity of the analysis, the evaluation was carried out by two independent observers. Five sections were randomly chosen for each animal. Approximately 1000 cells from cell population were counted by two observers at a magnification of $400 \mathrm{x}$ and the percentages of Ki-67 and Bcl-2 positive cells were calculated. All microscopic analyses were performed using a light microscope (Olympus, Tokyo, Japan).

The levels of Ki-67 and Bcl-2 expression were evaluated according to the scoring system of Seleit et al. [14]. The application of this system gives a score cells [(absent: <1\%), (mild: 1-10\%), (moderate: 10-50\%), (strong: $>50 \%$ )]. 


\section{Statistical analysis}

Statistical analysis was performed using Bonferroni Post Hoc test to assess statistical analysis for every individual pair in a group. $\mathrm{P}$ value less than or equal to 0.01 was considered statistically significant.

\section{Result}

\section{Histological analyses}

Microscopic examination of the rat's tongue of the saline/water and saline/honey groups revealed that the oral mucosa covering the underside of the rat's tongue being composed of keratinized stratified squamous epithelium. Besides, the lamina propria was generally thin, contained collagen fibers and small blood vessels. Groups of well formed striated muscles were also noticed beneath the lamina propria, and no inflammatory cells infiltration or congested blood vessels were seen (Figure 1, A1 and A2).

The MTX/water group showed that the ventral surface of the tongue revealed an obvious reduction in the thickness of the keratin and the epithelium, the supporting basement membrane was almost straight and congested blood vessels were detected in the underlying lamina propria. Vacuolar degeneration of some epithelial cells was also detected (Figure -1, B1 and B2).

The MTX/honey group showed increase in the thickness of the epithelium in comparison with the MTX/water group, the epithelium nearly restores its integrity and revealed marked improvement with the absence of congested blood vessels in the connective tissue (Figure $-1, \mathrm{C} 1$ and C2). The inflammatory infiltrates was not observed in all groups.

There was a statistically significant difference $(\mathrm{P}<0.01)$ present between MTX / water group $(19.22 \pm 3.56)$ and the other three groups regarding the thickness of the epithelium, but a statistically no significant difference $(\mathrm{P}>0.01)$ was observed between saline / water $(43.8 \pm 4.35)$ and saline/honey groups $(44.2 \pm 3.30)$, saline/water and MTX / honey groups $(41.43 \pm 2.99)$ or between saline / honey and MTX / honey groups.

There was a statistically significant difference $(\mathrm{P}<0.01)$ present between MTX/water group $(5.30 \pm 0.22)$ and the other three groups regarding the number of congested blood vessels. A statistically no significant difference $(\mathrm{P}<0.01)$ was observed between saline/water $(1.10 \pm 0.45)$ and saline/honey $(0.8 \pm 0.20)$, saline/water and MTX/ honey groups $(1.98 \pm 0.80)$ or between saline/honey and MTX/honey groups (Table-1).

\section{Immunohistochemical findings}

Photomicrograph of the ventral tongue region mucosa of rats in the saline/water group and saline/honey group revealed moderate Ki-67 immuno reactivity in nuclei of cells of basal and supra basal cells layers, and mild positive immunohistochemical expression of Bc1-2 in the epithelial cells cytoplasm of basal and supra basal cells layers. The MTX / water group showing mild positive immune reaction of Ki-67 in some nuclei of basal epithelial cells, and negative immunohistochemical expression of $\mathrm{Bcl}-2$ in the epithelial cells cytoplasm. The MTX / honey group showing mild positive immune reaction of Ki-67 in some nuclei of basal epithelial cells and mild immunohistochemical expression of $\mathrm{Bcl}-2$ in the epithelial cells cytoplasm (Figure 2).

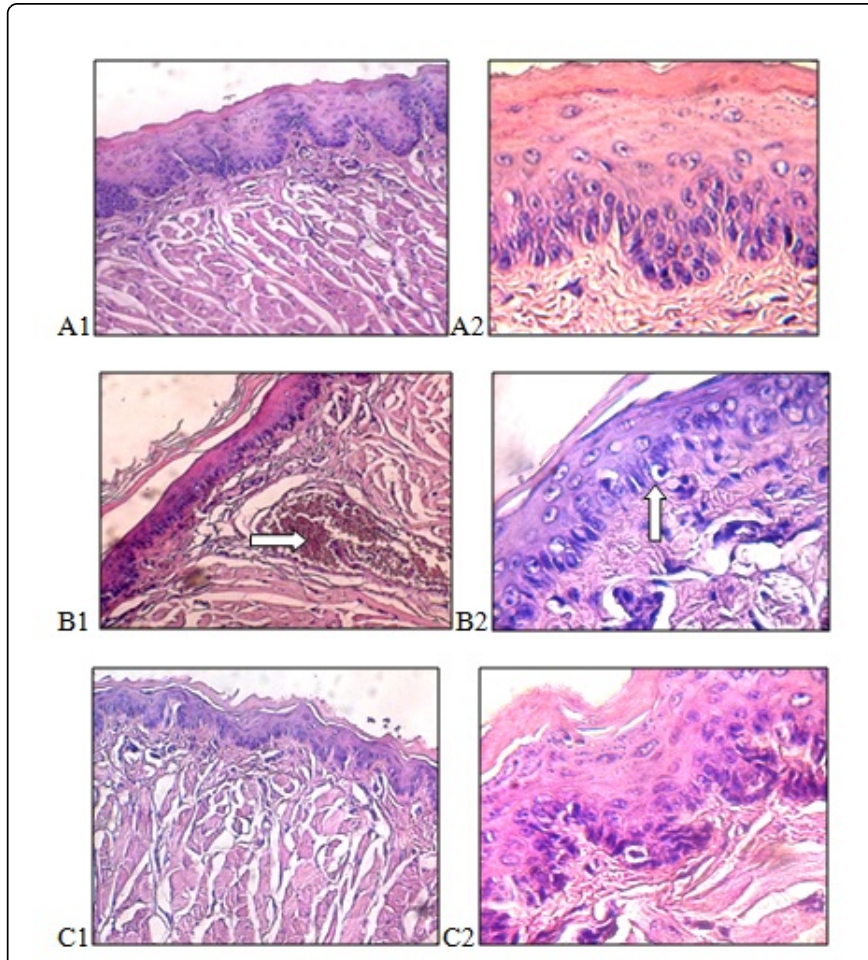

Figure 1: Photomicrograph of the ventral tongue mucosa of rat in saline / water group and saline / honey group, revealed normal keratinized squamous epithelium and connective tissue, which shows absence of subepithelial inflammatory cells and congested blood vessels (A1, H\&Ex100, A2, H\&Ex400). The MTX / water group showing decrease in the thickness of the epithelium and keratin layer with vascular hyperemia in the connective tissue (arrow), cytoplasmic vacuolation of some epithelial cells which appear with hyperchromatic nuclei (arrow), and flattening or shortening of rete ridges (B1, H\&Ex100, B2, H\&Ex400). The MTX / honey group showing increase in the thickness of the epithelium, nearly normal rete ridges with the absence of congested blood vessels in the connective tissue $(\mathrm{C} 1, \mathrm{H} \& \mathrm{Ex} 100, \mathrm{C} 2, \mathrm{H} \& \mathrm{Ex} 400)$

Statistical analysis showed that there was a statistically significant differences $(\mathrm{P}<0.01)$ present between saline/water group $(16.33 \pm 0.24)$ or saline/honey group $(17.14 \pm 0.22)$ and the other two groups in terms of the rate of proliferation, but a statistically no significant differences $(\mathrm{P}>0.01)$ was observed between MTX/water group (1.12 \pm $0.10)$ and MTX / honey group (2.16 \pm 0.35$)$, and between saline/water group and saline/honey group.

The Bcl-2 immune staining results in the MTX/honey treated group showed mild positive Bcl-2 immunoreaction in the cytoplasm of some epithelial cells, but it was negative in the MTX/water treated group. There was a statistically significant difference $(\mathrm{P}<0.01)$ present between MTX/water group $(0.01 \pm 0.02)$ and the other three groups in terms of the rate of anti-apoptosis. A statistically significant difference $(\mathrm{P}<0.01)$ was also observed between saline/water $(9.12 \pm 0.50)$ and MTX/honey group (4.16 \pm 0.22$)$, saline/honey $(9.98 \pm 0.61)$ and MTX/ honey group, but a statistically no significant difference $(\mathrm{P}>0.05)$ was observed between saline/water and saline /honey group (Table-2). 


\begin{tabular}{|c|c|c|c|c|}
\hline Groups & $\begin{array}{l}\text { Major } \\
\text { epithelial } \\
\text { thickness }\end{array}$ & P-value & $\begin{array}{l}\text { Number of } \\
\text { congested } \\
\text { blood } \\
\text { vessels }\end{array}$ & P-value \\
\hline Saline/water & $43.8 \pm 4.35$ & \multirow[t]{2}{*}{0.565} & $1.10 \pm 0.45$ & \multirow[t]{2}{*}{0.627} \\
\hline Saline/honey & $44.2 \pm 3.30$ & & $0.8 \pm 0.20$ & \\
\hline Saline/water & $43.8 \pm 4.35$ & \multirow[t]{2}{*}{0} & $1.10 \pm 0.45$ & \multirow[t]{2}{*}{0} \\
\hline MTX/water & $19.22 \pm 3.56$ & & $5.30 \pm 0.22$ & \\
\hline Saline/water & $43.8 \pm 4.35$ & \multirow[t]{2}{*}{0.119} & $1.10 \pm 0.45$ & \multirow[t]{2}{*}{0.327} \\
\hline MTX/honey & $41.43 \pm 2.99$ & & $1.98 \pm 0.80$ & \\
\hline Saline/honey & $44.2 \pm 3.30$ & \multirow[t]{2}{*}{0} & $0.8 \pm 0.20$ & \multirow[t]{2}{*}{0} \\
\hline MTX/water & $19.22 \pm 3.56$ & & $5.30 \pm 0.22$ & \\
\hline Saline/honey & $44.2 \pm 3.30$ & \multirow[t]{2}{*}{0.129} & $0.8 \pm 0.20$ & \multirow[t]{2}{*}{0.193} \\
\hline MTX/honey & $41.43 \pm 2.99$ & & $1.98 \pm 0.80$ & \\
\hline MTX/water & $19.22 \pm 3.56$ & \multirow[t]{2}{*}{0.009} & $5.30 \pm 0.22$ & \multirow[t]{2}{*}{0} \\
\hline MTX/honey & $41.43 \pm 2.99$ & & $1.98 \pm 0.80$ & \\
\hline
\end{tabular}

Table 1: Comparison between groups in the means and standard deviations of the histopathological parameters used in the study in rat's tongue mucosa following water or honey administration in female Albino rats post saline or methotrexate injection.

\section{Discussion}

Cancer patients receiving radiotherapy or chemotherapy for head and neck cancer usually suffers from oral mucositis which is considered as a severe complication, for which no effective intervention has been developed. Several studies were used topically applied honey for treatment of oral mucositis like Biswal et al. [15], Motallebnejad et al. [10], Rashad et al. [16], Khanal et al. [17], Abdulrhman et al. [18] and Sedighi et al. [19]. They showed that topically applied honey produced faster healing in patients with oral mucositis. However, despite using different types of honey, different scoring systems, and different inclusion criteria, all these trials showed about $50 \%$ decrease in the severity of oral mucositis in the honey arm. Parsons [20] found that there was no statistically significant difference in the severity of oral mucositis reported between those taking honey and those using standard forms of treatment.

All the patients reported that the honey was difficult to be tolerated once their mouth began to ulcerate, and patients found it difficult to manipulate the honey to coat all the oral mucosa. In addition to that, these studies did not address problems of tissue breakdown or impaired healing. For this reason, this study was conducted to found the systemic effect of honey on oral mucositis induced by MTX (60 $\mathrm{mg} / \mathrm{Kg}$ ) in rat model.

The present study showed that MTX cause a decrease in the thickness of the epithelium, vacuolar degeneration of epithelial cells, flattening or shortening of rete ridge, and vascular hyperemia.

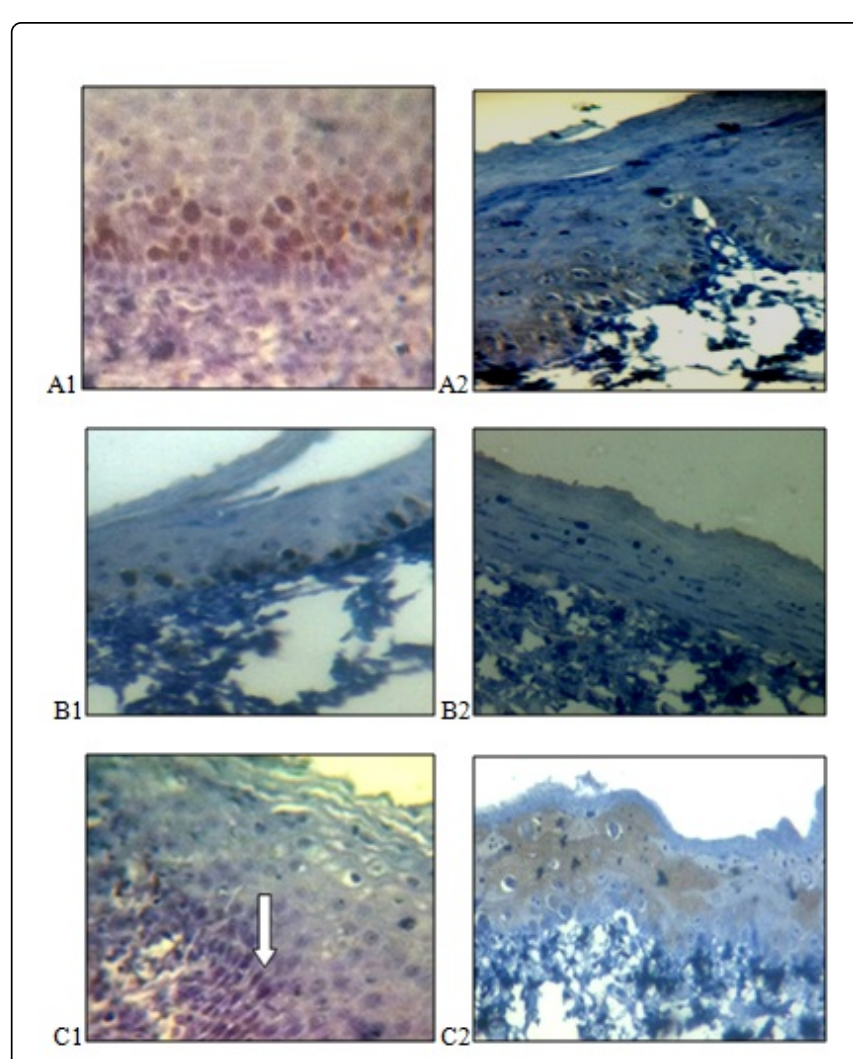

Figure 2: Photomicrograph of the ventral tongue region mucosa of rat in the saline/water group and saline / honey group revealed moderate Ki-67 immuno reactivity in nuclei of cells and mild positive immunohistochemical expression of $\mathrm{Bcl}-2$ in the epithelial cells cytoplasm of basal and supra basal cells layers (A1, A2, immunohistochemistry $\mathrm{x} 400$ ). The MTX / water group showing mild positive immune reaction of Ki-67 in some nuclei of basal epithelial cells (B1, immunohistochemistry $\mathrm{x} 400$ ), and negative immunohistochemical expression of Bc1-2 in the epithelial cells cytoplasm (B2, immunohistochemistry x400). The MTX / honey group showing mild positive immune reaction of Ki-67 in some nuclei of basal epithelial cells, arrow $(\mathrm{C} 1$, immunohistochemistry $\mathrm{x} 400$ ) and mild immunohistochemical expression of $\mathrm{Bcl}-2$ in the epithelial cells cytoplasm (C2, immunohistochemistry $\mathrm{x} 400)$.

The stem cell population in the oral mucosa has a very high cell turnover rate. This rapid course of cell proliferation and constant epithelial replacement renders the mucosa susceptible to the effects of cytotoxic drugs that affect rapidly proliferating cells. A complex mechanism is involved in the pathophysiology of mucositis. Chemotherapy generates ROS which are deleterious to the DNA of epithelial cells. ROS may induce a cascade of biological events, which in turn result in the synthesis of various pro-inflammatory cytokines. These cytokines target epithelium, endothelium and connective tissue, thereby causing tissue injury [21]. These inflammatory mediators cause further damage either directly or indirectly by increasing vascular permeability, thereby enhancing cytotoxic drug uptake into the oral mucosa [22].

Munaretto et al. [23] immune suppressed the mice with the subcutaneous injections of $2.5 \mathrm{mg} / \mathrm{kg}$ of MTX for three consecutive 
Page 5 of 6

days, the epithelial thickness of the ventral surface of the tongue was increased significantly in the second day of the experiment, but it decrease gradually later on. The number of blood vessels and inflammatory cells per field in the connective tissue was similar in control and experimental samples. The differences between the present result and other results in the methodology used prevent a direct comparison between them.

The present study also showed that the use of honey was more effective in alleviating oral mucositis in comparison to placebo. It significantly increases the thickness of oral epithelium and decrease the number of congested blood vessels in comparison with the MTX/ water treated group.

\begin{tabular}{|c|c|c|c|c|}
\hline Groups & Ki-67 & P-value & $\mathrm{Bcl}-2$ & P-value \\
\hline Saline/water & $16.33 \pm 0.24$ & \multirow{2}{*}{0.443} & $9.12 \pm 0.50$ & \multirow{2}{*}{0.195} \\
\hline Saline/honey & $17.14 \pm 0.22$ & & $9.98 \pm 0.61$ & \\
\hline Saline/water & $16.33 \pm 0.24$ & \multirow{2}{*}{0} & $9.12 \pm 0.50$ & \multirow{2}{*}{0} \\
\hline MTX/water & $1.12 \pm 0.10$ & & 0.02 & \\
\hline Saline/water & $16.33 \pm 0.24$ & \multirow{2}{*}{0} & $9.12 \pm 0.50$ & \multirow{2}{*}{0.007} \\
\hline MTX/honey & $2.16 \pm 0.35$ & & $4.16 \pm 0.22$ & \\
\hline Saline/honey & $17.14 \pm 0.22$ & \multirow{2}{*}{0} & $9.98 \pm 0.61$ & \multirow{2}{*}{0} \\
\hline MTX/water & $1.12 \pm 0.10$ & & $0.01 \pm 0.02$ & \\
\hline Saline/honey & $17.14 \pm 0.22$ & \multirow{2}{*}{0} & $9.98 \pm 0.61$ & \multirow{2}{*}{0.005} \\
\hline MTX/honey & $2.16 \pm 0.35$ & & $4.16 \pm 0.22$ & \\
\hline MTX/water & $1.12 \pm 0.10$ & \multirow{2}{*}{0.022} & $0.01 \pm 0.02$ & \multirow{2}{*}{0.003} \\
\hline MTX/honey & $2.16 \pm 0.35$ & & $4.16 \pm 0.22$ & \\
\hline
\end{tabular}

Table 2: Comparison between groups in the means and standard deviations of the immunohistochemical results in rat's tongue mucosa following water or honey administration in female Albino rats post saline or methotrexate injection.

Besides its sugar content, honey consists of several biologically active constituents such as vitamins, minerals, amino acids, proteins, as well as folic acids. This will help repair tissue directly [24]. Some of the flavonoids that have been identified in honey accelerate the healing process of oral mucositis by its anti-oxidant and free radical scavenging ability and it markedly suppressed the release of proinflammatory cytokines including TNF- $\alpha$ and IL-1 $\beta$ [25,26]. In addition to honey beneficial role as anti-inflammatory, it also has been endorsed to its antimicrobial as well as boosting of the immune system [27]. The data indicate that honey can modulate the molecular processes of initiation, promotion, and progression stages [28].

$\mathrm{Ki}-67$ is a nuclear proliferation-associated antigen expressed in the growth and synthesis phases of the cell cycle but not in the resting phase. This antigen provides information about the proportion of active cells in the cell cycle [29]. The bcl-2 gene encodes a protein located in the nuclear membrane, on the inner surface of mitochondria, and the endoplasmic reticulum. It is the most important gene of the bcl-2 family and has been reported to prolong the survival of cells by specifically inhibiting apoptosis. The balance between mitotic activity and apoptosis is thought to regulate normal development [30].
In the controlled groups, the Ki-67 expression was mostly seen in the basal and supra basal epithelial cells, this suggests that the epithelial basal and supra basal compartments have controlled proliferation rate but with a continuous proliferative capacity. A statistically no significant difference $(\mathrm{P}>0.01)$ was present between saline/water and saline/honey group in terms of the rate of proliferation and antiapoptosis. This is because honey is non-cytotoxic to normal cells [31].

In the MTX/water group, the methotrexate causes significant reduction in the Ki-67 and Bcl- 2 immune expression labeling indices in comparison with the control groups. MTX cause decreased DNA synthesis and cellular replication [32] and activates the apoptotic pathway [33].

In the MTX/honey group, the epithelium restores its integrity and revealed marked improvement, statistical analysis showed significant increase in Bcl-2 and no significant increase in $\mathrm{Ki}-67$ immune expression labeling indices in comparison with the MTX/water group. The epithelial cells may respond more frequently with arrest or senesce than with apoptosis.

\section{Conclusion}

In the present study, the combined treatment of MTX and honey ameliorated the cytotoxic changes in the ventral tongue mucosa of rat induced by MTX alone. Honey cause significant increase in the epithelial thickness, significant decrease in the number of congested blood vessels, nonsignificant increase in the Ki-67 immune expression, and significant increase in Bcl-2 immuno expression in comparison with non-honey MTX treated group.

\section{References}

1. Jemal A, Bray F, Center MM, Ferlay J, Ward E, et al. (2011) Global cancer statistics. CA Cancer J Clin 61: 69-90.

2. Benedek TG (2010) Methotrexate: from its introduction to nononcologic therapeutics to anti-TNF-Î̀. ClinExpRheumatol 28: S3-8.

3. Deeming GM, Collingwood J, Pemberton MN (2005) Methotrexate and oral ulceration. Br Dent J 198: 83-85.

4. Shih A, Miaskowski C, Dodd MJ, Stotts NA, MacPhail L (2003) Mechanisms for radiation-induced oral mucositis and the consequences. Cancer Nurs 26: 222-229.

5. Elting LS, Cooksley C, Chambers M, Cantor SB, Manzullo E, et al. (2003) The burdens of cancer therapy. Clinical and economic outcomes of chemotherapy-induced mucositis. Cancer 98: 1531-1539.

6. Maria de Sousa Sá O, Lopes NNF, Alves MTS, Lalla RV, Oliva MLV, et al. (2013) Glycine supplementation reduces the severity of chemotherapy. Natural Science 5: 972-978.

7. Sonis ST (2004) Oral mucositis in cancer therapy. J Support Oncol 2: 3-8.

8. Rosenthal DI (2007) Consequences of mucositis-induced treatment breaks and dose reductions on head and neck cancer treatment outcomes. J Support Oncol 5: 23-31.

9. Sampath Kumar KP, Bhowmik D, Chiranjib, Biswajit, Chandira MR (2010). Medicinal uses and health benefits of Honey: An Overview. J Chem Pharm Res 2: 385-395.

10. Motallebnejad M, Akram S, Moghadamnia A, Moulana Z, Omidi S (2008) The effect of topical application of pure honey on radiationinduced mucositis: a randomized clinical trial. J Contemp Dent Pract 9: 40-47.

11. Fijlstra M, Tissing WJE, Verkade HJ, Rings EHHM (2013) Parenteral feeding during methotrexate-induced gastrointestinal mucositis prevents weight loss in the rat. e- SPEN Journal 8: e95-e99. 
Citation: Al-Refai AS, Fawzi L, Khalil AK (2014) Effects of Kurdistan Honey on the Tongue of Chemotherapy Treated Albino Rats (Immunohistochemical Study) . J Cytol Histol 5: 272. doi:10.4172/2157-7099.1000272

Page 6 of 6

12. Al-Refai A Sultan, Al-Barazenchy H Ali, Khalil A Kamal (2014). Immunohistochemical study of the effect of green tea extract on methotrexate- induced oral mucositis in albino rats. J CytolHistol 5: 1-7.

13. Chandane RD, Jaju JB, Ghadlinge MS, Bhosale RR, Chandrakapure AR (2013) Effect of honey on hepatotoxicity induced by antitubercular drugs in albino rats. International Journal of Basic \& Clinical Pharmacology 2 : $177-181$.

14. Seleit IA, Asaad N, Maree A, Abdel Wahed M (2010) Immunohistochemical expression of p53 and $\mathrm{Ki}-67$ in cutaneous lupus erythematosus. J Egypt Women DermatolSoc 7: 5-15.

15. Biswal BM (2008) Current trends in the management of oral mucositis related to cancer treatment. Malays J Med Sci 15: 4-13.

16. Rashad UM, Al-Gezawy SM, El-Gezawy E, Azzaz AN (2009) Honey as topical prophylaxis against radiochemotherapy-induced mucositis in head and neck cancer. J LaryngolOtol 123: 223-228.

17. Khanal B, Baliga M, Uppal N (2010) Effect of topical honey on limitation of radiation-induced oral mucositis: an intervention study. Int J Oral MaxillofacSurg 39: 1181-1185.

18. Abdulrhman M, El Barbary NS, Ahmed Amin D, SaeidEbrahim R (2012). Honey and a mixture of honey, beeswax, and olive oil-propolis extract in treatment of chemotherapy-induced oral mucositis: a randomized controlled pilot study. PediatrHematolOncol 29: 285-292.

19. Sedighi I, Molaee S, Amanati A, Khoeinipourfar H, ShahlaNouri S (2013). Antimicrobial activity of natural honey: Topical application of pure natural honey in prevention of chemotherapy induced oral mucositis. Journal of Comprehensive Pediatrics 3: 138-142.

20. Parsons E (2011) An Investigation into the Effect of Manuka Honey on Oral Mucositis in Patients Receiving Radiation Therapy to the Head and Neck. (Thesis, Bachelor of Health Sciences with Honours). University of Otago, Dunedin, New Zealand.

21. Shih A, Miaskowski C, Dodd MJ, Stotts NA, MacPhail L (2003) Mechanisms for radiation-induced oral mucositis and the consequences. Cancer Nurs 26: 222-229.

22. Cawley MM, Benson LM (2005) Current trends in managing oral mucositis. Clin J OncolNurs 9: 584-592.
23. Munaretto JC, Ponzoni D, Haddad AS, Puricelli E (2011) Preliminary histological analysis of methotrexate induced oral mucositis: experimental study in mice. Passo Fundo 16: 144-148.

24. Robson V, Dodd S, Thomas S (2009) Standardized antibacterial honey (Medihoney) with standard therapy in wound care: randomized clinical trial. J AdvNurs 65: 565-575.

25. Alzahrani HA, Boukraa L, Bellik Y, Abdellah F, Bakhotmah BA, et al (2012) Evaluation of the antioxidant activity of three varieties of honey from different botanical and geographical origins. Glob J Health Sci 4: 191-196.

26. Candiracci M, Piatti E, Dominguez-Barragan M, Garcia-Antras D, Morgado B, et al. (2012) Anti-inflammatory activity of a honey flavonoid extract on lipopolysaccharide-activated N13 microglial cells. J Agric Food Chem 60: 12304-12311.

27. Meda A, Lamien CE, Millogo J, Romito M, Nacoulma OG (2004) Therapeutic uses of honey and honeybee larvae in central Burkina Faso. J Ethnopharmacol 95: 103-107.

28. Erejuwa OO, Sulaiman SA, Wahab MS (2014) Effects of honey and its mechanisms of action on the development and progression of cancer. Molecules 19: 2497-2522.

29. LazÄfr D, TÄ fban S, Sporea I, Dema A, Cornianu M, et al. (2010) Ki-67 expression in gastric cancer. Results from a prospective study with longterm follow-up. Rom J MorpholEmbryol 51: 655-661.

30. Ribeiro DA, Salvadori DM, Marques ME (2005) Abnormal expression of bcl-2 and bax in rat tongue mucosa during the development of squamous cell carcinoma induced by 4-nitroquinoline 1-oxide. Int J ExpPathol 86 375-381.

31. Hussein SZ, MohdYusoff K, Makpol S, MohdYusof YA (2013) Gelam honey attenuates carrageenan-induced rat paw inflammation via NF- $\hat{I}^{\circ} \mathrm{B}$ pathway. PLoS One 8: e72365.

32. Benedek TG (2010) Methotrexate: from its introduction to nononcologic therapeutics to anti-TNF-Ît. ClinExpRheumatol 28: S3-8.

33. Sonis ST (2004) The pathobiology of mucositis. Nat Rev Cancer 4: 277-284. 